\title{
Die naggesigte van Sagaria teen die agtergrond van konflik in die vroeë na-eksiliese gemeenskap in Juda 1
}

A L Bartlett

\section{ABSTRACT}

The Night Visions of Zechariah against the background of conflict in the early postexilic community in Judah

In this article Paul D Hanson's view that the Night Visions of Zechariah should be interpreted against the background of a situation of conflict in post-exilic society is taken up. His description of the text as a hierocratic document aimed at the restoration of the pre-exilic status quo is however challenged. It is indicated that the Night Visions should rather be read as text purporting to inspire its readers towards involvement in the processes of change in society. Different levels of meaning, reflecting various aspects of the conflict in the community, can be indicated in the text.

\section{INLEIDING}

Een van die mees verbeeldingryke pogings om die Naggesigte teen die agtergrond van omstandighede in die vroeë na-eksiliese gemeenskap in Juda te interpreteer, is dié van Paul D Hanson wat in sy uiteensetting daarvan uitgaan dat die teks spesifiek in die lig van die na-eksiliese konfliksituasie gelees moet word ${ }^{2}$.

Volgens Hanson het daar in die periode van restourasie ná die ballingskap twee groepe teenoor mekaar te staan gekom, elk met 'n eie program vir rekonstruksie 3 . Aan die een kant was daar 'n priesterlike, of "hiërokratiese" groep wat graag hulle eie posisie van beheer oor die tempelkultus wou herstel en wat derhalwe hulle rekonstruksieprogram gebaseer het op die model van voor-eksiliese instellings en strukture ${ }^{4}$. Aan die ander kant was daar 'n "visioenêre" groep wat die aansprake van die hiërokrate teengestaan het en wat teruggegryp het na modelle uit 'n meer argaïese periode, toe die instellings van Israel gekenmerk is deur ander sosiale strukture as dié van kort voor die ballingskap5. Die basis van eersgenoemde hiërokratiese program vir restourasie word volgens Hanson aangetref in die Verfassungsentwurf van Esegiël (Eseg 40-48)6, terwyl Deutero-Jesaja die basis vorm vir laasgenoemde, visioenêre program7. Die polarisasie tussen dié twee groepe het volgens Hanson aanleiding gegee tot 
toenemende konflik wat veral gewentel het om beheer van die sentrale kultus en die herbou van die tempel ${ }^{8}$.

In verskeie van sy publikasies interpreteer Hanson die Naggesigte van Sagaria as 'n produk van die hiërokratiese beweging'. Hoewel Sagaria, net soos die visioenêre, ook gebruik maak van die vorme van die profetiese eskatologie en in besonder van die visioen as genre, doen hy dit volgens Hanson met die uitsluitlike doel om populêre steun vir die hiërokratiese restourasieprogram te werf ${ }^{10}$. Hanson lê veral besondere klem op die verwantskap van die Naggesigte met die Verfassungsentwurf van Esegiël soos wat blyk uit sy beskrywing daarvan as "the original plan of the prophet Ezekiel which is being promulgated"11.

In hierdie artikel word daar aangesluit by Hanson se siening dat die Naggesigte van Sagaria teen die agtergrond van 'n situasie van konflik in die na-eksiliese gemeenskap verstaan moet word. Daar word egter aangetoon dat sy tipering daarvan as hiërokratiese geskrif wat gerig is op die herstel van die vooreksiliese status quo, nie volkome reg laat geskied aan die bedoeling van die teks nie en dat dit eerder gelees kan word as ' $n$ geskrif wat bedoel is om die lesers daarvan op visioenêre wyse te inspireer tot betrokkenheid by die prosesse van verandering in die samelewing.

\section{2}

\section{ONTLEDING VAN DIE NAGGESIGTE}

Op die oog af wek die teks van Sagaria 1:7-6:15 die indruk van sterk strukturele eenheid. Dit het veral te doen met die feit dat die verskillende Naggesigte (met die uitsondering van 3:1-10) almal volgens dieselfde onderliggende grondskema opgebou is. Hierdie grondskema bestaan uit die volgende basiselemente ${ }^{12}$ :

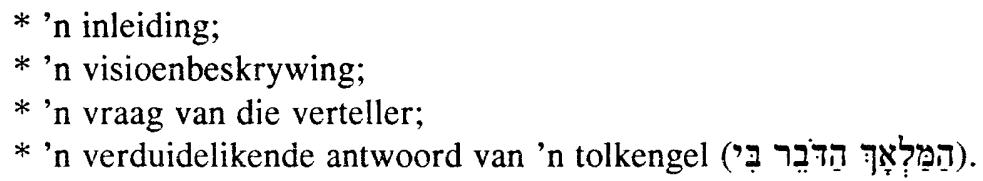

Op grond van hierdie strukturele simmetrie word die Naggesigte oor die algemeen as 'n samehangende literêre eenheid beskou'13.

Nadere literêr-kritiese ondersoek maak dit egter moontlik om binne 1:7-6:15 'n oorspronklike siklus van sewe Naggesigte te onderskei (1:8-17; 2:1-4 [1983-AV 1:18-21]; 2:5-9 [1983-AV 2:1-5]; 4:1-6aa.10b-14; $5: 1-4 ; 5: 5-11$ en $6: 1-8$ ) wat met die volgende toevoegings uitgebrei is: 
* die datum- en outeursformule in 1:714;

* 'n orakel in 2:10-17 (1983-AV 2:6-13) wat waarskynlik doel-bewus as sluitstuk vir die eerste drie Naggesigte geskep is ${ }^{15}$;

* 'n bykomende Naggesig in 3:1-1016 wat op sy beurt in 3:8b met 'n orakulêre fragment uitgebrei is ${ }^{17}$;

* 'n orakel in 4:6aß-10a ${ }^{18}$ wat uitgebrei is met die Erkenntnis-formule in $4: 9 b^{19}$;

* 'n profetiese tekenhandeling in 6:9-11 en 1420 wat op sy beurt uitgebrei is met die orakulêre gedeelte in 6:12-1321;

* 'n profetewoord met 'n Erkenntnis-formule in 6:15a-b en 'n slotvermaning in $6: 15 \mathrm{c}^{22}$.

Die volgende aanduidings word in die teks gevind van die relatiewe volgorde waarin die verskillende sekondêre gedeeltes tot die oorspronklike siklus toegevoeg is:

* 3:1-10 is waarskynlik eers ná 4:6aß-10a by die teks ingevoeg. Dit kan afgelei word van die feit dat die twee motiewe van die oë en die steen wat in 4:10 onderskeidelik deel vorm van die oorspronklike Naggesig en van die toegevoegde gedeelte, in 3:9 met mekaar verbind word en wel op só wyse dat die naas-mekaarstelling daarvan in 4:10 reeds veronderstel word ${ }^{23}$.

* Die feitlik woordelikse ooreenstemming van die Erkenntnis-formules wat in $2: 10-17,4: 9 b$ en $6: 15 a-b$ voorkom, dui daarop dat dié drie gedeeltes waarskynlik op dieselfde tydstip tot die teks toegevoeg is ${ }^{24}$.

* Dat 6:15a-b vóór 6:9-11.14 in die siklus opgeneem is, kan afgelei word van die feit dat eersgenoemde gedeelte wat handel oor die terugkeer van ballinge, ten nouste aansluit by 6:8 waar daar verwys word na die יהוז: wat tot rus gebring word in die Noordland (Babilon) - met die klaarblyklike bedoeling om die agtergeblewe ballinge aan te spoor om terug te keer na Jerusalem ${ }^{25}$.

* Die twee gedeeltes waarin die verhewe posisie van die hoëpriester 'n belangrike rol speel (3:1-10 en 6:9-11.14), het waarskynlik gelyktydig deel van die siklus geword ${ }^{26}$. Albei gedeeltes is waarskynlik daarna ook gelyktydig met die verwysings in 3:8b en 6:12-13 na 'n toekomstige messiaanse figuur (צמֵמה uitgebrei27.

* Die datum- en outeursformule in 1:7 en die slotvermaning in 6:15c is waarskynlik albei as deel van die redaksionele samevoeging van die verskillende dele van Sagaria 1-8 by die teks van die siklus gevoeg ${ }^{28}$. 
Die oorspronklike siklus van sewe Naggesigte vertoon struktureel 'n definitiewe simmetriese opbou ${ }^{29}$. Vanweë die verwantskap ten opsigte van uitbeelding en inhoud kan daar aan die eerste en die laaste Naggesigte (1:817 en 6:1-9) 'n omramingsfunksie toegeken word, terwyl die middelste Naggesig (4:1-4aa.10b-14) duidelik van die ander Naggesigte onderskei word deur die wyse waarop die onderliggende grondskema uitgebrei word met 'n meer uitvoerige inleiding en 'n meer komplekse vraag- en antwoordgesprek tussen die verteller en die tolkengel. Dit dien as aanduiding dat hierdie gedeelte as die sentrum van die oorspronklike siklus beskou kan word ${ }^{30}$.

Hieruit blyk dat die oorspronklike siklus grootliks in die vorm van 'n chiasme opgebou is ${ }^{31}$, wat soos volg skematies voorgestel kan word:
a $1: 8-17$
$6: 1-8$
b $2: 1-4$
$5: 5-11$
c $\quad 2: 5-9$
$5: 1-4$
d
$4: 1-4 a a, 10 b-14$

Hierdie chiastiese patroon versterk die innerlike progressie wat op inhoudelike vlak in die siklus aangetoon kan word: vanaf die skynbare gebeurloosheid in die volkerewêreld (eerste Naggesig) tot by die

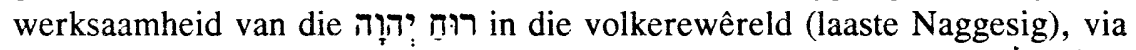
die sentrale visie op die aanwesigheid van Jahwe as die אָדון כָּל הָאָר (middelste Naggesig).

Die invoeging van die bykomende materiaal gee aanleiding tot die volgende wysigings van die opbou van die siklus:

* Die toevoeging van 3:1-10 en van 4:6aß-10a lei tot 'n aansienlike uitbreiding van die sentrum.

* Die toevoeging van $2: 10-17,6: 9-11.14$ en 6:15a-b gee aan-leiding tot 'n addisionele struktuurvlak (tussen $\mathrm{c}$ en $\mathrm{d}$ hierbo).

* Die omramingsfunksie van die eerste en die laaste Naggesigte word tot 'n mate verswak deur die toevoeging van 1:7 en $6: 15 \mathrm{c}$. Hierdie toevoegings gee ook aanleiding tot ' $n$ addisionele struktuurvlak in die teks.

Die opbou van die teks in sy finale gestalte kan soos volg voorgestel word: 

a $(1: 7)$
$(6: 15 c)$
b $\quad 1: 8-17$
$6: 1-8$
c $\quad 2: 1-4$
$5: 5-11$
d
$2: 5-9$
$5: 1-4$
$\mathrm{e}$
$(2: 10-17)$
$(6: 9-15 b)$
f

Op grond van die gegewens met betrekking tot die relatiewe volgorde waarin die verskillende gedeeltes tot die oorspronklike siklus toegevoeg is, kan die volgende vlakke in die teks van 1:7-6:15 onderskei word:

* Vlak I: Die oorspronklike siklus.

* Vlak II: 4:6aß-10a word in die middelste Naggesig ingevoeg en wel op só 'n wyse dat dit 'n prominente posisie reg in die middel van die siklus verkry.

* Vlak III: 2:10-17 en 6:15a-b word as sluitstukke aan die einde van die eerste drie en die laaste drie Naggesigte gevoeg. Terselftertyd word 4:6aß-10a met die Erkenntnis-formule in 4:9b aangevul.

* Vlak IV: Die teks word verder uitgebrei met die invoeging van 3:110 naas 4:1-14 in die sentrum van die siklus en van 6:9-11.14 in aansluiting by die sluitstuk in 6:15a-b.

* Vlak V: Laasgenoemde twee toevoegings word op hulle beurt gewysig met die toevoeging van $3: 8 b$ en $6: 12-13$.

* Vlak VI: As deel van die redaksionele samevoeging van die verskillende dele van Sagaria 1-8 word 1:7 en 6:15c aan die begin en die einde van die siklus gevoeg.

Die toevoeging van bykomende gedeeltes tot die teks van die oorspronklike siklus het telkens 'n verskuiwing van fokus tot gevolg:

* Die toevoeging van 4:6aß-10a laat val die klem op die herbou van die tempel en die belangrike rol van Serubbabel as koninklike tempelbouer.

* Met die invoeging van $2: 10-17,4: 9 b$ en $6: 15 a-b$ verskuif die fokus aan die een kant na die terugkeer van ballinge om deel te neem aan 
die rekonstruksie van die samelewing en die herbou van die tempel, en aan die ander kant na die posisie van die profeet as die gevolmagtigde gesant van Jahwe.

* Met die toevoeging van 3:1-10 en 6:9-11,14 verskuif die klem na die verhewe posisie van die hoëpriester Josua wat as gevolmagtigde van Jahwe die leidende rol in die samelewing beklee.

* Die uitbreiding van laasgenoemde twee gedeeltes met die toevoeging van $3: 8 b$ en $6: 12-13$ laat die fokus verskuif na die optrede van 'n toekomstige eskatologies-messiaanse figuur. In albei gevalle lei dit tot 'n relativering van die verhewe uitsprake oor die hoëpriester.

* Met die toevoeging van 1:7 word die Naggesigtesiklus binne die tydshistoriese raamwerk van gebeure in die tweede regerings-jaar van die Persiese koning Darius geplaas en word dit eksplisiet verbind aan die outeurskap van die profeet Sagaria ben-Iddo. Terselfdertyd word daar 'n verband gelê met die ander dele van Sagaria 1-8 en met die boek Haggai, waar feitlik identiese datum- en outeursformules gebruik word.

'n Opvallende verskil tussen die oorspronklike siklus en die latere toevoegings tot die teks is die wyse waarop daar van simboliese taal gebruik gemaak word. In elkeen van die oorspronklike Naggesigte word daar ' $n$ beskrywing gegee van een of meer simboliese objekte waarvan die betekenis telkens deur die tolkengel aan die verteller verduidelik moet word ${ }^{32}$. In 3:1-10 en in 6:9-11,14 word daar nie 'n beskrywing gegee van simboliese objekte nie, maar van 'n histories-herkenbare figuur (die hoëpriester Josua), met wie daar in albei gevalle 'n simboliese handeling uitgevoer word ${ }^{33}$. In die res van die toegevoegde gedeeltes word daar slegs op insidentele wyse van simbole gebruik gemaak (byvoorbeeld in 4:7 waar die "hoë berg" dien as simbool van probleme tydens die herbou van die tempel ${ }^{34}$ ) en word dit in die meeste gevalle gekenmerk deur 'n totale afwesigheid van simboliese taalgebruik.

'n Soortgelyke verskil tussen die oorspronklike siklus en die toegevoegde gedeeltes kan waargeneem word in die rolspelers wat in die onderskeie teksdele figureer. In die oorspronklike siklus is die tolkengel en die verteller die mees prominente rolspelers, terwyl Jahwe uitgebeeld word as die persoon wat agter die skerms die eintlike dryfkrag van die gebeure is ${ }^{35}$. Die ander rolspelers is of ander hemelwesens of simboliese figure. Die een geval waar daar wel 'n toespeling op spesifieke persone gemaak

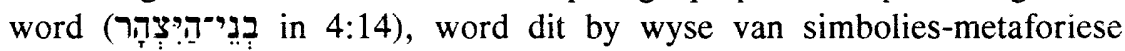
taalgebruik gedoen ${ }^{36}$. In die toegevoegde gedeeltes is die situasie egter anders: 
* In nie een van dié gedeeltes speel die tolkengel enige rol nie, terwyl die verteller self ook meer op die agtergrond figureer as in die oorspronklike siklus.

* In 4:6aß-10a word by name na die Dawidiese leiersfiguur Serubbabel verwys.

* In 2:10-17 en 6:15a-b word daar na dié wat woon in die "dogter van Babel" (2:11) en "die wat ver is" (6:15a) verwys. In die Erkenntnisformules wat deel uitmaak van hierdie teksvlak, verwys die profeet na homself as 'n gesant van Jahwe.

* In 3:1-10 en 6:6-11.14 word daar by name na die hoëpriester Josua verwys en in laasgenoemde perikoop ook by name na 'n aantal persone wat uit die ballingskap teruggekeer het. In 3:1-10 is daar wel ook, soos in die geval van die oorspronklike siklus,

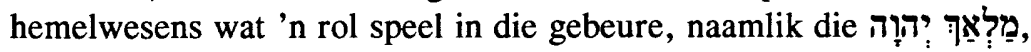

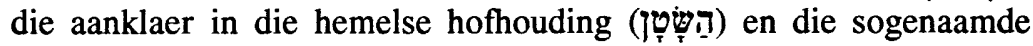
עִ עִדִ.

* In 3:8b en 6:11-12 word daar met die metaforiese benaming צֶמֵָה na 'n toekomstige koninklik-messiaanse figuur verwys en in laasgenoemde geval ook na die hoëpriester bloot as "'n priester".

* In 1:7 word daar by name verwys na die Persiese koning Darius en die profeet Sagaria ben-Iddo.

Die indruk wat deur die oorspronklike siklus gewek word van gebeure wat op 'n vlak tussen die gewone aardse en die bo-aardse afspeel en waarvan die betekenis op onthullende wyse bekend gemaak moet word, word dus toenemend in die daaropvolgende groeiproses van die teks teëgewerk deurdat die vertelling nader aan die gewone gebeure van die aardse bestaan gebring word.

Uit dit wat tot op hierdie punt oor die totstandkoming van die teks van die Naggesigtesiklus gesê is, is dit duidelik dat daar waarskynlik met verskillende outeurs vir die onderskeie vlakke van die teks gereken moet word.

Die outeur van vlak I (die oorspronklike Naggesigtesiklus) kan waarskynlik bestempel word as 'n navolger van Deutero-Jesaja wat die ideale van hierdie geskrif wou bevorder in die tydperk van rekonstruksie ná die ballingskap ${ }^{37}$. Sy perspektief op die ballingskap as 'n teken van Jahwe se toorn verraai terselftertyd die invloed van deuteronomistiese teologie ${ }^{38}$. Dat sy toekomsvisie die bevryding van vreemde oorheersing ingesluit het, blyk uit die verskillende gedeeltes wat handel oor Jahwe se 
optrede teen die nasies. Ten opsigte van die leierskapskwessie in die gemeenskap verteenwoordig hy 'n kompromisposisie soos wat blyk uit die feit dat hy hom in 4:14 ten gunste van 'n diargiese leierskapstruktuur gegrond op die gelykberegtiging van die koninklike en die priesterlike leiersfigure uitspreek ${ }^{39}$. Uit die polemiese strekking van 2:5-9 kan afgelei word dat die outeur gekant was teen 'n rekonstruksieprogram wat gerig was op 'n blote herstel van die vooreksiliese status quo $0^{40}$, terwyl dit uit die polemiek in 5:1-4 blyk dat hy ook 'n kampvegter was vir die herstel van die eiendomsregte van die teruggekeerde ballinge ${ }^{41}$. Die verwysings in die teks na kultiese aangeleenthede dui op 'n kennis van priesterlike sake en sou as aanduiding kon dien dat die outeur moontlik ook 'n verbintenis met priesterlike kringe in die gemeenskap gehad het ${ }^{42}$.

Ook die outeur van vlak II (4:6aß-10a) het hom waarskynlik onder die navolgers van Deutero-Jesaja bevind ${ }^{43}$ en het die ideale van hierdie profeet vergestalt gesien in die leierskap van Serubbabel en sy optrede met betrekking tot die herbou van die tempel. Hy openbaar egter 'n versigtigheid ten opsigte van die meer ekstreme messiaanse verwagtinge wat daar in sekere kringe rondom die persoon van Serubbabel gekoester is ${ }^{44}$. Hieruit kan die afleiding gemaak word dat sy visie nie noodwendig die beëindiging van Persiese opperheerskappy ingesluit het nie. Sy verswyging van die naam van die hoëpriester Josua en sy bestryding van die teenstand teen die leierskap van Serubbabel dui moontlik op 'n polemiese ingesteldheid teenoor die aansprake van die Sadokitiese priestergroep. Met die invoeging van sy teks in die Naggesigtesiklus wou hy waarskynlik die klem op 'n diargiese leierskapstruktuur verminder en die siklus benut as 'n middel om sy eie pro-Serubbabel standpunt te bevorder.

: Die outeur van vlak III sluit veral in 2:10-17 só nou aan by die eerste drie Naggesigte en verteenwoordig in só 'n mate dieselfde perspektief as die oorspronklike siklus, dat daar waarskynlik gereken kan word dat dieselfde persoon die outeur van albei dele van die teks was ${ }^{45}$. Met die invoeging van die addisionele materiaal wou die outeur klaarblyklik aan die een kant sterker klem lê op sekere motiewe in die oorspronklike siklus (die terugkeer van groot getalle ballinge, die beëindiging van vreemde oorheersing en die herbou van Jerusalem en die tempel), en aan die ander kant sy eie optrede as profeet wat deur Jahwe gestuur is, verdedig teenoor diegene wat dit betwyfel het.

Die persoon wat op vlak IV verantwoordelik was vir die uitbreiding van die siklus (met die invoeging van 3:1-10 en 6:9-11.14), vind sterk aansluiting by die denke in priesterlike kringe en het waarskynlik behoort tot die groep wat hulle beywer het vir 'n teokratiese bestel onder leiding 
van die Sadokitiese priesters-elite ${ }^{46}$. Die verswyging van die naam van Serubabel dui waarskynlik daarop dat hierdie gedeeltes tot die oorspronklike siklus toegevoeg is met die doel om die klem op die rol van Serubbabel in die herbou van die tempel te relativeer en om die fokus te verskuif na die leiersrol van die hoëpriester Josua. Die voltooiing van die tempel en die herinstelling van die kultus word by implikasie in 3:9-10 as 'n voorwaarde vir die aanbreek van 'n nuwe heilsbedeling beskryf, terwyl dit in die res van die siklus gesien word as een van die vele fasette van die heilswending wat besig is om voltrek te word ${ }^{47}$. Daarmee polemiseer die outeur teen 'n perspektief waarvolgens die kultus slegs 'n deel uitmaak van 'n breër samelewingsordening, en verleen hy aan die Naggesigtesiklus die karakter van 'n strydgeskrif ter bevordering van 'n perspektief waarvolgens die totale samelewingsordening vanuit die kultus bedink word.

Op die volgende vlak in die proses van teksvorming (vlak V), tree 'n outeur op wat in sy bewerking van die teks van die Naggesigte van materiaal met sterk messiaanse bowetone gebruik maak en wel op só manier dat hy die posisie van die hoëpriester ondergeskik stel aan dié van 'n toekomstige koninklike figuur ${ }^{48}$. In 'n sekere sin herstel hy daarmee die oorspronklike diargiese perspektief van die oorspronklike siklus, maar met dié verskil dat die hoëpriester in sy visie nie as die gelyke van die koninklike leiersfiguur funksioneer nie. Die messiaanse terminologie wat deur die outeur gebruik word, dui daarop dat hy ook die herstel van die monargie, bevry van Persiese oorheersing, in die vooruitsig gestel het.

Met die redaksionele bewerking op vlak VI word die verband van die Naggesigtesiklus met die res van Sagaria 1-8 en Haggai bevestig49.

Hieruit blyk dat die teks in sy verskillende gestaltes die konflik tussen verskillende groepe in die samelewing reflekteer. Hierbo is daarop gewys dat daar uit die polemiek in 2:5-9 afgelei kan word dat daar onder die teruggekeerde ballinge meningsverskil was oor die tipe rekonstruksieprogram wat gevolg moes word, terwyl die polemiek in 5:1-4 dui op ernstige spanning tussen die teruggekeerde ballinge en die bevolking wat in die land agtergebly het oor die herstel van eersgenoemde groep se eiendomsregte ${ }^{50}$. Deur na sy teëstanders te verwys as "diewe" en "meinediges" assosieer die outeur hom sterk met die belange van die teruggekeerde ballinge en die herstel van hulle regte.

Die eerste, weliswaar indirekte teken van konflik rondom die leierskap in die gemeenskap is die simboliese uitbeelding van 'n diargiese leierskapstruktuur in 4:14. Daaruit kan die afleiding gemaak word dat daar meer as een groep was wat aanspraak gemaak het op leierskap, en ook 'n groep wat ten gunste van die "historiese kompromis" van 'n "regering van nasionale eenheid" was. 
In die gedeeltes wat agtereenvolgens tot die teks toegevoeg is, kom daar 'n duideliker beeld van sowel die konflik as die groepe wat daarby betrokke was, te voorskyn. Die een groep was pro-Serubbabel gesind en het hulle klaarblyklik beywer vir die herstel van die Dawidshuis se leiersrol in een of ander vorm. Binne hierdie groep was daar waarskynlik egter ook verskillende beklemtoninge: aan die een kant was daar diegene wie se ideale op die heroprigting van 'n soewereine monargie onder leiding van 'n Dawidiese koning gerig was (vgl Sag 6:12-13); aan die ander kant was daar diegene wat met 'n prominente leiersrol vir Serubbabel tevrede was sonder dat hulle spesifiek begerig was om die soewereiniteit van Juda te herstel (vgl die wyse waarop uitgesproke messiaanse sentimente in 4:6aß-10a vermy word).

Teenoor die pro-Serubbabel groep was daar klaarblyklik ook 'n pro-Josua groep wat hulle vir die konsentrasie van die leierskap in die hande van die Sadokitiese hoëpriester beywer het. Uit die verantwoordelikhede wat in 3:7 aan die hoëpriester opgedra word, blyk dat hierdie groep hulle nie net ten doel gestel het om die prerogatiewe van die vooreksiliese konings aan die hoëpriester oor te dra nie, maar ook sekere pligte wat tradisioneel die verantwoordelikheid van die Leviete was ${ }^{51}$. Dit veronderstel 'n verdere faset van die konflik in die gemeenskap: dié tussen die Sadokitiese priesters wat onder die teruggekeerde ballinge getel het en die Levitiese priesters wat tydens die ballingskap in die land agtergebly het ${ }^{52}$.

Die geheelindruk is dié van 'n redelik gediversifieerde konfliksituasie waarin daar nie net sprake van twee botsende partye is nie, maar van 'n verskeidenheid groepe wat onderling verskil het oor 'n hele reeks aangeleenthede ${ }^{53}$.

Teenoor Hanson se tipering van die Naggesigte as literatuur wat bedoel is om die status quo te bestendig, dui die resultate van hierdie oorsig daarop dat die teks eerder as 'n dokument (of 'n reeks dokumente) gelees kan word wat gerig is op die verandering van die status quo. Die enigste fase in die groeiproses van die teks waar daar sprake is van 'n verbintenis tot 'n Sadokitiese restourasieprogram, is op vlak IV met die toevoeging van $3: 1-10$ en 6:9-11.14. Die sterk beklemtoning van die leiersrol van die Sadokitiese hoëpriester en die sleutelposisie van die tempelkultus in hierdie gedeeltes verleen wel aan die teks op hierdie vlak die karakter van 'n hiërokratiese geskrif. Hierdie gedeeltes is egter ook gerig op die verandering van die status quo aan die hand van 'n idealistiese beeld van 'n samelewing onder Sadokitiese leierskap.

Die groot leemte in die benadering van Hanson is die onkritiese wyse warop die bipolêre konflikmodel wat hy as uitgangspunt neem, 
hanteer word. Hierdie model word toegelaat om op ' $n$ byna ideologiese wyse in sy eksegetiese werk te funksioneer deurdat dit enersyds sy perspektief op belangrike aspekte van die teks verblind, en andersyds nie aan kritiese kontrole onderwerp word nie. Dit blyk onder andere uit die feit dat hy nie rekenskap gee van die talle ooreenkomste tussen die Naggesigte en Deutero-Jesaja nie en ook nie aandag gee aan die polemiese wyse waarop daar in die teks omgegaan word met motiewe uit die Verfassungsentwurf van Esegiël nie. 'n Verdere gevolg is die simplistiese rekonstruksie wat Hanson van die ná-eksiliese samelewing en van die konflik tussen verskillende groepe in die gemeenskap bied ${ }^{54}$. Sy oordrewe aanwending van polariteite ${ }^{55}$ lei daartoe dat hy die ná-eksiliese konflik tot slegs twee strydende groepe reduseer, terwyl daar op oortuigende gronde aangevoer kan word dat die situasie waarskynlik baie meer kompleks daar uitgesien het.

Dit lei tot die vraag of die bi-polêre model die mees geskikte is en of dit nie verkieslik sou wees om 'n model te gebruik wat aan die een kant rekening hou met die moontlikheid van meer komplekse konfliksituasies, en aan die ander kant ruimte vir sowel konflik as konsensus in 'n samelewing laat nie ${ }^{56}$.

Ten spyte van die leemtes in Hanson se benadering het sy bereidwilligheid om aan die hand van 'n sosiologiese model deur te dring tot die leefwêreld agter tekste opnuut die aandag daarop gevestig dat tekste nie bloot lewelose studie-objekte of artefakte is nie, maar dat dit uitdrukking gee aan die denke en ideale van mense van vlees en bloed en dus ook ' $n$ venster open op die sosio-politieke weklikheid waarin hierdie mense hulle bevind het ${ }^{57}$.

Die Naggesigte van Sagaria vertel van 'n persoon wat die omstandighede van sy tyd as donker en neerdrukkend beleef het - 'n tyd waarin daar ernstig oor die aard van God se betrokkenheid by die leefwêreld van die geloofsgemeenskap getwyfel is. In hierdie omstandighede leer hierdie persoon om weer te droom en om opnuut 'n visie te kry van die oorweldigende teenwoordigheid van God wat soos die helder lig van 'n kandelaar (vgl Sag 4:1 ev) skyn in die duisternis van die wêreld. Hy ontdek opnuut hoedat hierdie heilvolle aanwesigheid lei tot die verandering en die vernuwing van omstandighede wat vasgeloop het in skynbaar onveranderlike realiteite. Deur hierdie visioen oor te vertel leer hy sy lesers om saam met hom te droom en saam met hom betrokke te raak by dit wat besig is om rondom hulle te gebeur. 
In die konflik van sy tyd word sy vertelling deur ander vertellers opgeneem en telkens met die ideale van hulle eie groep in verband gebring. Enersyds gee hulle daarmee uitdrukking aan die begeerte om God se teenwoordigheid as 'n konkrete werklikheid te ervaar. Andersyds loop hulle daarmee die gevaar om God te probeer vasvang in beperkte strukture wat nie reg laat geskied aan sy grootheid en die ontwykende aard van sy aanwesigheid nie.

Maar God laat Hom nie beperk nie. Hy is God-met-ons, maar Hy gaan ons ook altyd weer vooruit. Daarom pas dit om af te sluit met met die woord van Sagaria 2:17 (1982-AV 2:13):
"Wees stil voor Jahwe, al wat leef, want Hy kom te voorskyn uit sy heilige woonplek."

\section{NOTAS:}

Hierdie artikel is 'n samevatting van die belangrikste resultate van A $\mathrm{L}$ Bartlett, Die Naggesigte van Sagaria. In gesprek met P D Hanson, Pretoria 1994, 'n proefskrif wat voltooi is onder leiding van prof W S Prinsloo, Departement Ou Testament, Universiteit van Pretoria.

P D Hanson, The dawn of apocalyptic. The historical and sociological roots of Jewish apocalyptic eschatology, Philadelphia 1975, 247.

Ibid, "Old Testament apocalyptic re-examined", Interpretation 25 (1971), 465.

Ibid, $a w, 229-234$.

Ibid, "Jewish apocalyptic against its Near Eastern environment", $R B 78$ (1971), 51 .

Ibid, $a w, 247$.

Ibid, $a w, 218$.

Ibid, $R B 78$ (1971), 53-54.

Ibid, $a w, 240-262$; ibid, The people called. The growth of community in the Bible, San Fransisco 1986, 261-266; ibid, "In defiance of death: Zechariah's symbolic universe" in: Love \& death in the ancient Near East Essays in honor of Marvin H Pope, Edited by J H Marks \& R M Good), Guilford 1987, 173-179. 
K Seybold, Bilder zum Tempelbau. Die Visionen des Propheten Sacharja, Stuttgart 1974, 44 en 48; J Jeremias, Die Nachtgesichte des Sacharja. Untersuchungen zu ihrer Stellung im Zusammenhang der Visionsberichte im Alten Testament und ihrer Bildmaterial, Göttingen 1977, 10; A S van der Woude, Zacharia, Nijkerk 1984, 29.

14 Seybold, $a w, 11-12$; Van der Woude, $a w, 31$; R J Coggins, Haggai, Zechariah, Malachi, Sheffield 1987, 25-27.

H-G Schöttler, Gott inmitten seines Volkes. Die Neuordnung des Gottes Volkes nach Sacharja 1-6, Trier 1987, 78.

Bartlett, $a w, 75-76$.

P L Redditt, “Zerubbabel, Joshua and the Night Visions of Zechariah", $C B Q$ 54 (1992), 254.

Seybold, a w, 14-15; W Rudolph, Haggai - Sacharja 1-8 - Sacharja 9-14 Maleachi, Gütersloh 1976, 62; Jeremias, $a w, 176$; Redditt, CBQ 54 (1992), 249-250.

Seybold, $a w, 20$; Jeremias, $a w, 40$.

Coggins, $a w, 46 ; \mathrm{H}$ G Reventlow, Die Propheten Haggai, Sacharja und Maleachi, Göttingen 1993, 32-33.

Petersen, $a w, 275-277$.

Reventlow, $a w, 73$.

$23 \quad$ Bartlett, $a w, 186$.

$24 \quad$ Ibid, $a w, 73$.

25 Van der Woude, $a w, 117-118$

26 Bartlett, $a w, 189-190$.

27 R A Mason, "The prophets of restoration", in: Israel's prophetic tradition (Essays in honour of Peter R Ackroyd, Edited by R Coggins, A Phillips \& M Knibb), Cambridge 1982, 147-148; C L Meyers \& E M Meyers, Haggai, Zechariah 1-8, New York 1987, 203. 
K Koch, Die Profeten II. Babylonisch-persische Zeit, Stuttgart 1980, 174; Van der Woude, $a w, 29$; Reventlow, $a w, 39-40$.

H Gese, "Anfang und Ende der Apokalyptik, dargestellt am Sacharjabuch", ZTK 70 (1973), 37; Jeremias, $a w, 12-13$; Van der Woude, $a w, 29$.

J C Baldwin, Haggai - Zechariah - Malachi, London 1972, 85; C Stuhlmueller, Rebuilding with hope. A commentary on the books of Haggai and Zechariah, Grand Rapids 1988, 60-61.

Koch, $a w, 170$; Coggins, $a w, 48$.

Seybold, $a w, 17$; Jeremias, $a w, 20$; Coggins, $a w, 46$.

G Fohrer, Die Propheten des Alten Testaments. Band 5: Die Propheten des ausgehenden 6. und 5. Jahrhunderts, Gütersloh 1976, 76; P R Ackroyd, Israel under Babylon and Persia, Oxford 1986, 230; Stuhlmueller, a w, 87; B Halpern, "The ritual background of Zechariah's temple song", $C B Q 40$ (1978), 187.

Bartlett, $a w, 123-124$.

Reventlow, $a w, 59$.

K Galling, Studien zur Geschichte Israels im persischen Zeitalter, Tübingen 1964, 113-115; Seybold, a w, 84; C Westermann, Prophetische Heilsworte im Alten Testament, Göttingen 1987, 87 en 93; Bartlett, $a w, 133-137,158$ en $259-260$.

Van der Woude, $a w, 20$.

Galling, $a w, 137$; Meyers \& Meyers, $a w, 259$.

Bartlett, $a w, 154-155$.

Van der Woude, $a$ w, 110; J H le Roux, "Teologie in 'n krisis", in: Rewolusie en reïterpretasie (Onder redaksie van F E Deist \& J H le Roux), Kaapstad 1987, 148.

S Japhet, "Sheshbazzar and Zerubbabel - against the background of the historical and religious tendencies of Ezra-Nehemiah", ZAW 94 (1982), 7678 . 
Rudolph, $a w, 89$; Schöttler, $a w, 78$.

Bartlett, $a w, 188-190$ en 199-200.

Meyers \& Meyers, $a w, 213$.

Petersen, $a w, 210-211$.

Seybold, $a w, 11-12$; Coggins, $a w, 25-27$.

Van der Woude, $a w, 110$.

Petersen, $a w, 204-205$; Schöttler, $a w$, 332-334; J M O'Brien, Priest and Levite in Malachi, Atlanta 1990, 13-16.

53 F E Deist, "Prior to the dawn of apocalyptic", in: The exilic period. Aspects of apocalypticism (Edited by W C van Wyk), Pretoria 1984, 21-32.

54 I Willi-Plein, "Paul D Hanson, The Dawn of apocalyptic. The historical and sociological roots of Jewish apocalyptic eschatology", VT 29 (1979), 124; W J Wessels, "Haggai from a historian's view", OTE 1/2 (1988), 59.

R P Carroll, "Twilight of prophecy or dawn of apocalyptic?", JSOT 14 (1979), 25; W S Prinsloo, "Ou Testament Teologie vandag" in: Ou Testament Teologie: gister, vandag en môre (Onder redaksie van W S Prinsloo \& W Vosloo), Pretoria 1987, 32.

56 Vergelyk die beskouing van Dahrendorff dat 'n konflikmodel saam met 'n integrasionistiese model gebruik behoort te word om reg te laat geskied aan die kompleksiteit van samelewings, $\mathrm{R}$ Dahrenorff, "Toward a theory of social conflict", in: Sociological theory (Edited by W L Wallace), Chicago 1969, 217.

$57 \quad$ Carroll, JSOT 14 (1979), 17; Wessels, OTE 1/2 (1988), 58. 